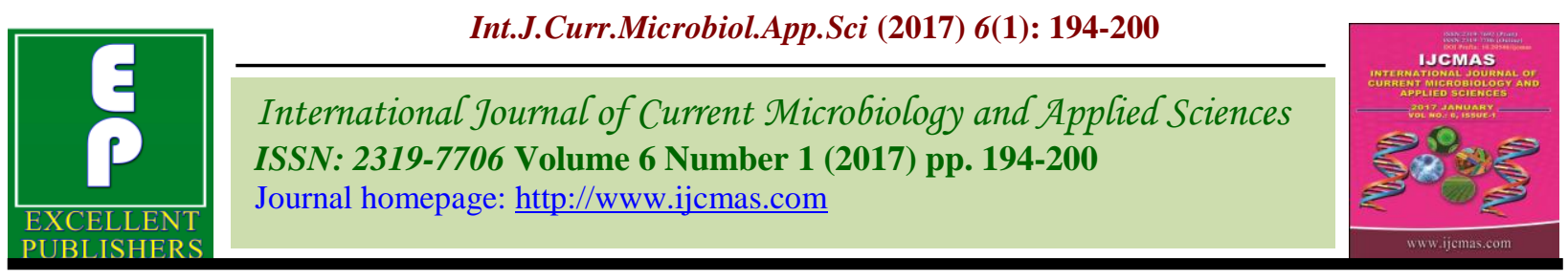

Review Article

http://dx.doi.org/10.20546/ijcmas.2017.601.024

\title{
Emerging Trends in Improving Viability, Advanced Stability Techniques and Health Claims of Healthy Microbiome - The Probiotics
}

\author{
R. Sangami ${ }^{1,2} *$ and S. Radhai $\mathrm{Sri}^{3}$ \\ ${ }^{1}$ Research and Development Centre, Bharathiar University, Coimbatore, India \\ ${ }^{2}$ Department of Clinical Nutrition, Sri Ramachandra University, \\ Chennai- 600116, Tamilnadu, India \\ ${ }^{3}$ Department of Nutrition, Food service management and Dietetics, PSG College of \\ Arts and Science, Coimbatore-641014, Tamilnadu, India \\ *Corresponding author
}

\section{A B S T R A C T}

\section{Keywords}

Healthy

Microbiome,

Probiotics,

Saccharomyces

cerevisiae.

Article Info

Accepted:

12 December 2016

Available Online:

10 January 2017
In the recent past there has been increased interest in microbial or functional food supplements which are now referred as probiotics. Food and beverage products particularly dairy foods are enormously considered to be well liked carriers of probiotic organisms and drastically extend the option for regular consumption of probiotics in the human diet. It is essential that commercialized probiotic products which make health claims meet the minimum criterion of one million viable probiotic cells per milliliter of product at the expiration date. The term prebiotics refers to non digestible food ingredients that are considered to encourage the growth and activity of probiotic organisms. Increasing evidence are revealed in favour of the claims of beneficial effects attributed to probiotics and the health properties are strain specific and are impacted by the various mechanisms. Current technological innovations provide ways to overcome probiotic stability and viability issues offering new options such as encapsulation and lyophilization. Thus this review gives an insight of health claims, various probiotic food products and about advanced stability and viability enhancing techniques in the emerging field of probiotic research.

\section{Introduction}

Functional foods serve nutrients and physiologically active components for a healthy living. The development and consumption of functional foods, or foods that promote health beyond providing basic nutrition, are on the rise (Prem Prakash Dewani, 2004). In most countries, the products related to having a healthy gut dominate the functional foods market one of such kind is "Probiotic" food products. The term Probiotic emerged from greek term "Pro bios" stating 'For Life', which is used to name microorganisms that are associated with the beneficial effects for humans and animals (Carlos Ricardo Soccoll et al., 2010). The most widely accepted definition of probiotics was admitted during a joint conference of the Food and Agriculture 
Organization (FAO) of the United Nations and World Health Organization (WHO) in 2001, stating probiotics as "Live microorganisms which, when administered in adequate amounts, confer a health benefit on the host" (Schlundt, 2012).

Dead bacteria, products derived from bacteria, or end products of bacterial growth also may impart certain benefits, but these derivatives are not considered to be probiotics because they are not alive when administered (Mary Ellen Sanders et al., 2007). The global probiotic market reported with a compound annual growth rate of $12.6 \%$ from 2009 to 2014. On the other hand the probiotic product industry in India was estimated to be around Rs 20.6 million with a projected annual growth rate of $22.6 \%$ until 2015 (Frost and Sullivan Research Service, 2009).

Prebiotics refers to non digestible food ingredients that are considered to encourage the growth and activity of probiotic organisms. Non-digestible oligosaccharides particularly inulin, its hydrolysis product oligofructose and (trans) galactooligo saccharides, fulfill all the criteria for prebiotic classification.

Prebiotics are found naturally in many foods such as whole grains, onions, bananas, garlic, honey, leeks, artichokes and can also be extracted from plants such as inulin from chicory root (Francisco Guarner et al., 2011). Several plant fibres (prebiotics) and a few LABs (probiotics) have documented significant effects to improve both the function of the innate immune system, the physical barrier, and increase resistance to disease (Stig Bengmark, 2012). Food products with synergistic combinations of pro- and prebiotics are termed as synbiotics supplements and these products are quickly gaining attention as functional foods.

\section{Criteria for selection of Probiotic Organism}

The right selection and application of a probiotic strains in food materials exhibits fundamental impacts on qualitative aspects of final products, namely safety and health benefits (strain specific), sensory attributes and even, the price. Thus the probiotic strain to be selected must be evaluated with its characteristics for growth and survival during manufacture, storage and after consumption, during transit through the stomach and small intestine because the selected strain must retain the characteristics that give rise to the health effects.

The initial screening and selection of probiotic organism includes testing of the following important criteria such as phenotype and genotype stability including plasmid stability, carbohydrate and protein utilization patterns, acid and bile tolerance, survival and growth, bile metabolism, intestinal epithelial adhesion properties, production of antimicrobial substances, antibiotic resistance patterns, ability to inhibit known gut pathogens, spoilage organisms and immunogenicity (Tuomola et al., 2001). Assessment of stability can also be a challenge, since factors such as chain length and injury may challenge the typical assessment of colony-forming units, as well as in vivo function. Besides the mentioned criteria's probiotic culture should aid in a good flavor production in the carrier that has been used and good acid production in fermented products.

Extensive investigations of probiotics have been greatly enhanced by the research of new microbes for future probiotic bacteriotherapy applications. The most commonly used organisms in probiotic preparations are the lactic acid bacteria $(\mathrm{LAB})$, these are found in large numbers in the gut of healthy humans and animals and 
are Generally Regarded as Safe (GRAS). Organisms other than lactic acid bacteria, which are currently being used in probiotic preparations, include Bacillus sp., Bifido bacterium sp., Enterococcus sp., Streptococcus sp., yeasts (e.g. Saccharomyces cerevisiae and Saccharomyces boulardii) and filamentous fungi (e.g. Aspergillus oryzae). Initially probiotic preparations were available in the form of powders, tablets, capsules, pastes or sprays depending on the animal or human receiving the supplement and the condition to be treated currently many food products has been formulated with the incorporation of probiotic organisms (S. Parvez et al., 2006)

\section{Viability}

Viability of probiotic microorganisms, namely, the number of viable and active cells per gram or $\mathrm{mL}$ of probiotic food products at the moment of consumption is the most critical value of these products as it determines their medicinal efficacy (Khorbekandi et al., 2011). It is also equally important for probiotic health claim the bacterial level should be a minimum dosage of 108-109 probiotic CFU/ ml-1 or CFU / g1 , which corresponds to an intake of $100 \mathrm{~g}$ product containing 106-107 CFU / ml-1 or CFU / g-1 per day (Lorens-Hattingh et al., 2001).

Foods containing probiotic bacteria act as their vehicles or carriers until cells reach the intestinal tract. The food itself may have an important influence on the functional attributes of the probiotic strain, as it is incorporated in food during its passage through the different biological barriers of the gastrointestinal tract (Fig:1). In this way, the physicochemical attributes of food (fat and protein content, type of proteins, sugars, $\mathrm{pH}$, titrable acidity etc.), certain food ingredients (flavoring agents, thickeners, sweeteners, stabilizers, etc.) and added functional ingredients (bioactive components) to which probiotic bacteria are exposed, may affect their performance in this complex matrix by modifying their functionality and efficacy (Gabriel Vinderola et al., 2011). The others factors such as molecular oxygen, redox potential, hydrogen peroxide, bacteriocins, short chain fatty acids, microbial competitions, packaging materials and packaging conditions, rate and proportion of inoculation, stepwise/stage-wise fermentation, micro-encapsulation, milk solid non-fat content, fortification of milk with nutrients, heat treatment of milk, incubation temperature, storage temperature, carbonation, cooling rate of the product and scale of production may also tend to influence the efficacy of the probiotic strain (Amir Mohammad Mortazavian et al., 2012).

\section{Probiotic Novel food products}

Concerning the health benefits, various probiotics are introduced to food matrices. Probiotic microorganisms are available in three different types for direct or indirect human consumption: 1) culture concentrate to be added to a food mostly as dried or deep-freeze form subjected for industrial or home uses, 2) food products either as fermented or non-fermented and 3) dietary supplements in the form of drug products in powder, capsule or tablet forms (Tannis, 2008). Fermented foods, particularly dairy foods are commonly used as probiotic carriers, as they provide an important contribution to the human diet in many countries because fermentation is an inexpensive technology which preserves food, improves its nutritional value and enhances its sensory properties. However, the increasing demand for new probiotic products has encouraged the development of other food matrices to deliver probiotics. 
Significant attention has been paid to dairy products containing probiotic bacteria such as fermented milks, ice cream, various types of cheese, baby-food, milk powder, frozen dairy desserts, whey-based beverages, sour cream, buttermilk, normal and flavored liquid milk, acidophilus milk, concentrated milk and chocolates. The newly developed novel nondairy products are vegetarianbased products, cereal-based products, vegetable and fruit juice, noni juice, tender coconut water, soya based products, oatbased desserts, confectionary products, breakfast cereals and baby foods (Mortazavian et al., 2011).

\section{Health Benefits}

Increasing evidence are revealed in favour of the claims of beneficial effects attributed to probiotics including improvement of intestinal health, enhancement of the immune response, reduction of serum cholesterol, and reducing risk of certain cancers which are strain specific. Consuming probiotic foods also exerts immune enhancing effect by immunomodulation influencing several aspects of the acquired and innate immune response by inducing phagocytosis and $\operatorname{Ig} \mathrm{A}$ secretion, modifying T-cell responses, enhancing Th1 responses, and attenuating Th2 responses (Isolauri et al., 2001).

Various other benefits includes synthesizing and enhancing the bioavailability of nutrients, decreasing the prevalence of allergy in susceptible individuals, reducing symptoms of irritable bowel syndrome (IBS), inflammatory bowel disease (IBD) and pouchitis. Eradication of Helicobacter pylori, reducing the symptoms of Necrotizing enterocolitis, hepatic encephalopathy, nonalcoholic fatty liver disease, prevention of systemic infections such as gastrointestinal and nosocomial respiratory tract infections (Hojsak et al.,
2010). Promising positive effects on probiotic supplementation were published in major surgery patients (gastric resection, pancreatic resection, liver transplantation) and in severe necrotizing acute pancreatitis. The use of probiotics, especially Lactobacillus species, has been shown to be effective in treating bacterial vaginosis (Ya, et al., 2010). Prebiotics such as lactulose are commonly used for the prevention and treatment of the complication of cirrhosis. (Shukla et al., 2011).

\section{Advanced techniques for increasing the stability}

It is understood that stability and viability of probiotics is affected as a result of their exposure to high temperature, oxygen, low $\mathrm{pH}$ and light. Naturally many LAB may excrete exo-polysaccharides (EPS) to protect themselves from harsh conditions however, the protection afforded is not sufficient (Shah, 2002). Many researches using different approaches to improve survival of probiotic cultures are on the go and these include pre-exposure of probiotic cultures to sub-lethal stresses and incorporation of micro-nutrients such as peptides and amino acids, genetic, immobilization, two-step fermentations, use of oxygen-impermeable containers and microencapsulation (Özer et al., 2009). Among these techniques, microencapsulation is relatively new and has been investigated by various researchers.

Microencapsulation is a process by which solids, liquids or gases are packaged into miniature. This process stabilizes the probiotics, increases their survival during processing and storage, controls the oxidative reaction, ensures sustained or controlled release at a specific target site and improves shelf life (Anal et al., 2007). Studies reported improved viability of $>105 \mathrm{cfu} \mathrm{g}-1$ in the 
encapsulated probiotic product compared to counts of $<103$ cfu g-1 when nonencapsulated organisms were used (Mortazavian et al., 2010). Microencapsulation of free probiotic cells reported to increase the viability by $\geq 2 \log$ cycles in fermented milks during a refrigerated storage period.

Both physical and chemical microencapsulation techniques are used in both pharmaceutical and food industries. Physical methods such as pan coating, airsuspension coating, centrifugal extrusion, spray drying, spray coating, annular jet, spinning disk, spray cooling, spray chilling, extrusion coating, fluidized bed coating, liposome entrapment, centrifugal extrusion and rotational suspension separation.

Chemical methods include interfacial polym erization, in-situ polymerization, matrix polymerization and extrusion. Studies on microencapsulation technique indicate that extrusion and emulsion are the mostly commonly used methods and probiotic cultures enclosed within solid fat microcapsules tend to retain both their activity and vitality well (Krasaekoopt et al., 2003).

Fig.1 Factors Affecting the Viability of Probiotic Strains

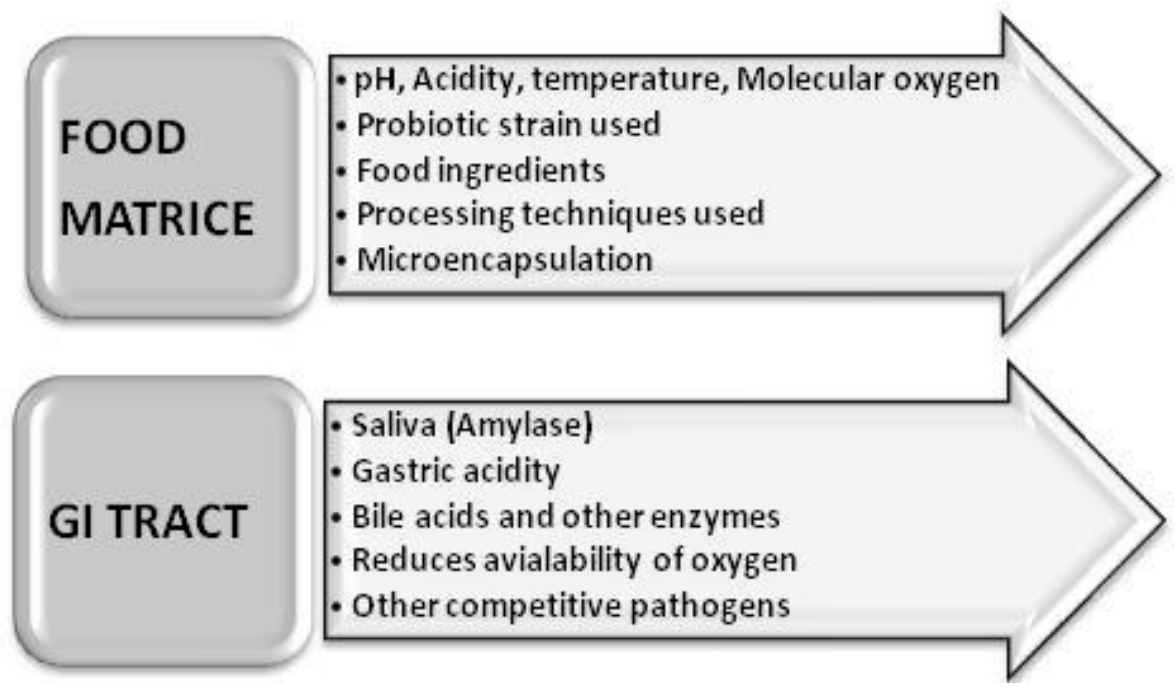

Powdered foods have much longer shelf life at an ambient temperature. Drying can be achieved by different methods such as freeze drying, spray drying, microwave drying and vacuum drying. Freeze drying is the best process for maintaining the viability of the bacterial cells used for preparing starter culture cells. Huge diversity exists with relevance to the materials used for encapsulation of probiotics. Some of the materials used are alginate, $\mathrm{\kappa}$-carrageenan, locust bean gum, cellulose acetate phthalate, chitosan, gelatin, cellulose, pectin, whey protein and rennet (Heidibach et al., 2009). These are used either as supporting materials or as gelling agents in encapsulating the probiotic strain.

In conclusion, increasing awareness of consumer health and interest in functional foods to achieve a healthy lifestyle has resulted in the need for food products with versatile health-benefiting properties. Probiotic as functional foods represent a huge growth potential for the food industry and may be explored through the 
development of innovative ingredients, processes, and products. It is also well understood that probiotic bacteria subjected to be selected for commercial use in food and therapeutic products must retain the characteristics for which they were originally selected. The safety of probiotics is tied to their intended use, which includes consideration of potential vulnerability of the consumer, nature of the microbe being used, dose and duration of consumption, and both the manner and frequency of administration. More researches in developing innovative trendy probiotic food products involving advanced stability and viability enhancing techniques integrated with in vivo clinical trials should be carried out to maximally utilize the probiotics in our day to day life.

\section{References}

Amir Mohammad Mortazavian, Reza Mohammadi and Sara Sohrabvandi. 2012. Delivery of Probiotic Microorganisms into Gastrointestinal Tract by Food Products, New Advances in the Basic and Clinical Gastroenterol., Prof. Tomasz Brzozowski (Ed.), ISBN: 978-953-51-0521-3, Pg No: 121 - 146.

Anal, A.K. and Singh, H. 2007. Recent advances in microencapsulation of probiotics for industrial and applications and targeted delivery. Trends in Food Sci. Technol., 18: 240-251.

Carlos Ricardo Soccol, Luciana Porto de Souza Vandenberghe, Michele Rigon Spier, Adriane Bianchi Pedroni Medeiros, Caroline Tiemi Yamaguishi, Juliano De Dea Lindner, Ashok Pandey and Vanete Thomaz-Soccol. 2010. The Potential of Probiotics: A Review, Food Technol. Biotechnol., 48(4) Pg: 413.

Elina Tuomola, Ross Crittenden, Martin Playne, Erika Isolauri, and Seppo Salminen. 2001. Quality assurance criteria for probiotic bacteria, American J. Clin. Nutri., vol. 73 no. 2 393s-398s.
Francisco Guarner, Aamir G. Khan, James Garisch, Rami Eliakim, Alfred Gangl, Alan Thomson, Justus Krabshuis, Ton Le Mair. 2008. Probiotics and prebiotics, World Gastroenterology Organization Practice Guideline.

Frost and Sullivan Research Service. 2009. Probiotics in Foods and BeveragesStrategic assessment of the Indian Market.

Gabriel Vinderola, Ana Binetti, Patricia Burns and Jorge Reinheimer. 2011. Cell Viability and Functionality of Probiotic Bacteria in Dairy Products, Front Microbiol., 2: 70:1-6.

Heidibach T., Forst P. \& Kulozik U. 2009. Microencapsulation pf probiotic cells by means of rennet-gelation of milkproteins. Food Hydrocolloids, 23: 16701677.

Hojsak, I., Abdovińá, S., Szajewska, H., Milosevińá, M., Krznarińá, Z., Kolacek, S. 2010. Lactobacillus GG in the prevention of nosocomial gastrointestinal and respiratory tract infections. Pediatrics, 125: e1171-7.

Isolauri, E., Y. Sütas, P. Kankaanpää, H. Arvilommi, and S. Salminen. 2001. "Probiotics: effects on immunity," American J. Clin. Nutri., vol. 73, no. 2, pp. 444S-450S.

Korbekandi, H., A.M. Mortazavian and Iravani, S. 2011. Technology and stability of probiotic in fermented milks. In Probiotic and Prebiotic Foods: Technology, Stability and Benefits to the human health, pp. 131-169; Shah, N., A.G. Cruz and J.A.F Faria. Eds.) Nova Science Publishers, New York.

Krasaekoopt, W., B. Bhandari and H. Deeth. 2003. Evaluation of encapsulation techniques of probiotics for yoghurt. Int. Dairy J., 13: 3-13.

Lourens-Hattingh, A., Viljoen, B.C. 2001. Growth and survival of a probiotic yeast in dairy products. Food Res. Int., 34, 791-796.

Mary Ellen Sanders, Glenn Gibson and Harsharnjit, S., Gill. 2007. Council for 
Agricultural Science and Technology. CAST. Probiotics: Their Potential to Impact Human Health. Issue Paper 36. Pg: $1-20$.

Mortazavian, A.M., Mohammadi, R., Cruz, A.G., Faria, J.A.F. 2011. Technology and Stability of Probiotics in Dairy Desserts, In: Shah NP. Ed.) In Probiotic and Prebiotic Foods: Technology, Stability and Benefits to the human health, pp. 233-252; Shah, N., A.G. Cruz and J.A.F Faria. Eds.) Nova Science Publishers, New York.

Mortazavian, A.M., R. Khosrokhvar, H. Rastegar and G.R. Mortazaei. 2010. Effects of dry matter standardization order on biochemical and microbiological characteristics of freshly made probiotic Doogh. Iranian fermented milk drink). Ital. J. Food Sci., 22: 98-102.

Özer, B., Kirmaci, H.A., Şenel, E., Atamer, M., Hayaloğlu, A. 2009. Improving the viability of Bifidobacterium bifidus BB12 and Lactobacillus acidophilus LA-5 in white-brined cheese by microencapsulation. Int. Dairy J., 19, 22-29.

Parvez, S., K.A. Malik, S. Ah Kang and H.-Y. Kim. 2006. Probiotics and their fermented food products are beneficial for health, J. Appl. Microbiol., Vol: 100, Issue 6, Pg: 1171-1185.

Prem Prakash Dewani. 2004. Probiotic Dairy Foods, Beverage and Food World. 31. 8. 52-59.

Schlundt, J. 2012. Health and nutritional properties of probiotics in food including powder milk with live lactic acid bacteria, Report of a Joint FAO/WHO Expert Consultation on Evaluation of Health and Nutritional Properties of Probiotics in Food Including Powder Milk with Live Lactic Acid Bacteria, FAO/WHO.

Shah, N.P. 2002. The exopolysaccharides production by starter cultures and their influence on textural characteristics of fermented milks. Symposium on New Developments in Technology of Fermented Milks. International Dairy J., 3rd June, Comwell Scanticon, Kolding, Denmark. Abstract p5.

Shukla, S., Shukla, A., Mehboob, S., Guha, S. 2011. Meta-analysis: the effects of gut flora modulation using prebiotics, probiotics and synbiotics on minimal hepatic encephalopathy. Aliment Pharmacol. Ther., 33: 662-71.

Stig Bengmark. 2012. Integrative medicine and human health - the role of pre-, proand synbiotics, Clinical and Translational Med., 1:6.

Tannis, A. 2008. Probiotic rescue: how you can use probiotics to fight cholesterol, cancer superbugs, digestive complaints and more, John Wiley \& Sons Canada, Ltd P:269

Ya, W., Reifer, C., \& Miller, L.E. 2010. Efficacy of vaginal probiotic capsules for recurrent bacterial vaginosis: a double-blind, randomized, placebocontrolled study. American J. Obstetrics and Gynecol., 203(2): p. 120.e1-120.e6.

\section{How to cite this article:}

Sangami, R., and Radhai Sri, S. 2017. Emerging Trends in Improving Viability, Advanced Stability Techniques and Health Claims of Healthy Microbiome - The Probiotics. Int.J.Curr.Microbiol.App.Sci. 6(1): 194-200. doi: http://dx.doi.org/10.20546/ijcmas.2017.601.024 